\title{
UNA VISIÓN CRÍTICA DE LA LEY ORGÁNICA 2/2018, DE 5 DE DICIEMBRE, DE REFORMA DE LA LOREG PARA GARANTIZAR EL DERECHO DE SUFRAGIO DE TODAS LAS PERSONAS CON DISCAPACIDAD
}

LUIS A. GÁLVEZ MUÑOZ 


\section{SUMARIO}

I.- INTRODUCCIÓN. II.- LA FALACIA DE LA OBLIGATORIEDAD DE LA REFORMA. II.1. Plano internacional. II.2. Plano constitucional. III.- LA INJUSTA DESVALORACIÓN DEL ARTÍCULO 3 DE LA LOREG OBJETO DE LA REFORMA. III.1. Finalidad constitucionalmente relevante. III.2. Idoneidad, necesidad y proporcionalidad. IV.- LA DEFICIENTE ARTICULACIÓN DE LA REFORMA. V.- BIBLIOGRAFÍA CITADA 


\title{
UNA VISIÓN CRÍTICA DE LA LEY ORGÁNICA 2/2018, DE 5 DE DICIEMBRE, DE REFORMA DE LA LOREG PARA GARANTIZAR EL DERECHO DE SUFRAGIO DE TODAS LAS PERSONAS CON DISCAPACIDAD
}

\author{
LUIS A. GÁLVEZ MUÑOZ* \\ Catedrático de Derecho Constitucional, Universidad de Murcia.
}

\section{I.- INTRODUCCIÓN}

El 21 de noviembre de 2018, en vísperas de la celebración del día internacional de las personas con discapacidad, las Cortes Generales aprobaron, tras una tramitación de casi 15 meses, la Ley Orgánica 2/2018, de 5 de diciembre, de reforma de la Ley Orgánica 5/1985, de 19 de junio, del Régimen Electoral General (en adelante, LOREG), para garantizar el derecho de sufragio de todas las personas con discapaci$\mathrm{dad}^{1}$. Y lo hicieron, además, en el mismo año en que se cumplía el décimo aniversario de la entrada en vigor de la Convención sobre los Derechos de las Personas con Discapacidad de 2006 (en adelante, la Convención), base y acicate de esta y otras relevantes reformas en nuestro ordenamiento jurídico ${ }^{2}$.

Es una ley breve, pues su objeto fundamental es suprimir de nuestro ordenamiento la causa de privación del ejercicio del derecho de sufragio regulada en los artículos 3.1 b) y c) y 3.2 de la LOREG, que consiste en la declaración de «incapacidad» para dicho ejercicio que pueden adoptar los jueces que conocen de los procesos de modi-

* Facultad de Derecho, Universidad de Murcia, C/Santo Cristo, 1, 30001, Murcia. Email: lgalvez@ um.es

El 21 de noviembre es el día en que la Ley fue aprobada por el Senado, sin introducirse modificaciones respecto del texto remitido por el Congreso de los Diputados, y, por ello, en el que quedó definitivamente aprobada por las Cortes Generales.

2 Su entrada en vigor se produjo el 3 de mayo de2008, una vez recibido el número requerido de instrumentos de ratificación o adhesión. 
ficación de capacidad o internamiento psiquiátrico ${ }^{3}$. La Ley no se queda, sin embargo, en esta eliminación, pues, además de ello, y en estrecha conexión, dota de nuevo contenido al apartado 2 del artículo 3 con la exigencia de que el sufragio se ejerza «consciente, libre y voluntariamente, cualquiera que sea su forma de comunicarlo y con los medios de apoyo que requiera»; e introduce una nueva disposición adicional en la LOREG, la octava, por la que «quedan sin efecto las limitaciones en el ejercicio del derecho de sufragio establecidas por resolución judicial fundamentadas jurídicamente en el apartado 3.1. b) y c) de la Ley Orgánica 5/1985, de 19 de junio, ahora suprimidas» ${ }^{4}$.

La Ley de reforma, que resultó aprobada por unanimidad — aunque no sin grandes esfuerzos-, fue recibida de la forma esperada por los diferentes sectores que se acercaban a ella: con alborozo no disimulado por quienes eran los destinatarios fundamentales de la norma - las personas con discapacidad- y sus asociaciones, entre ellas el Comité Español de Representantes de Personas con Discapacidad (CERMI); con sorpresa, en general, por parte de la ciudadanía, que desconocía, en su inmensa mayoría, la situación en la que se encontraba la regulación del derecho de sufragio de las personas con discapacidad intelectual o mental y su aplicación; y con fuerte división de opiniones en el ámbito jurídico — por aplicadores y estudiosos de la normasobre su oportunidad, el contenido que se le ha dado y los términos concretos en que ha quedado formulada, aunque con una tendencia mayoritaria de respaldo 5 .

Nuestra opinión, en términos generales, es crítica con la reforma y nos proponemos explicarlo en este trabajo. No nos parece, en primer lugar, que la reforma fuera jurídicamente obligada, por la incompatibilidad del artículo 3.1 de la LOREG con el derecho internacional y la Constitución, como se ha dicho de forma recurrente por sus defensores; creemos, en segundo término, que con ella se elimina una justificada e importante garantía jurídica del sistema constitucional, en términos de bienes y

3 Para ello se suprime tanto la prescripción contenida en los apartados b y c del artículo 3.1 de la LOREG de que carecen de derecho de sufragio «los declarados incapaces en virtud de sentencia judicial firme, siempre que la misma declare expresamente la incapacidad para el ejercicio del derecho de sufragio»y «los internados en un hospital psiquiátrico con autorización judicial, durante el período que dure su internamiento siempre que en la autorización el juez declare expresamente la incapacidad para el ejercicio del derecho de sufragio», como el mandato complementario del artículo 3.2 de que «los Jueces o Tribunales que entiendan de los procedimientos de incapacitación o internamiento deberán pronunciarse expresamente sobre la incapacidad para el ejercicio del sufragio y que en el supuesto de que ésta sea apreciada, lo comunicaran al Registro Civil para que se proceda a la anotación correspondiente».

4 La disposición adicional octava de la LOREG concluye señalando: «Las personas a las que se les hubiere limitado o anulado su derecho de sufragio por razón de discapacidad quedan reintegradas plenamente en el mismo por ministerio de la ley».

5 Así se evidenció desde el primer momento. Así, por ejemplo, vid Centro de Estudios Políticos y Constitucionales (2019). Seminario Derecho de sufragio y discapacidad, celebrado en el Centro de Estudios Políticos y Constitucionales el 3 de abril de 2019, con ponencias de académicos y participación de miembros de la Junta Electoral Central, jueces, fiscales y representantes de asociaciones de personas con discapacidad. Resumen accesible en http://www.cepc.gob.es/actividades/agenda/2019/03/06/seminario-derecho-de-sufragio-y-discapacidad. 
valores de gran significación; y consideramos, finalmente, que no se ha articulado de manera adecuada, dado el tenor de las disposiciones complementarias señaladas. Vamos a verlo.

\section{II.- LA FALACIA DE LA OBLIGATORIEDAD DE LA REFORMA}

Desde la aprobación de la Convención fue cristalizando y extendiéndose en diversos ámbitos la idea de que la posibilidad, prevista en el artículo 3 de la LOREG, de poder privar del ejercicio del derecho de sufragio a las personas sometidas a un proceso de modificación de capacidad o de internamiento psiquiátrico, por razón de incapacidad electoral, era contraria a la Convención y a la Constitución, con la lógica consecuencia de considerar que era obligada e inevitable la reforma de la LOREG para impedirlo y poner en pie de igualdad a estos ciudadanos. Se puede decir que se creó una especie de communis opinio jurídico-social pro reforma, con la que, sin embargo, discrepamos.

Veamos separadamente los dos elementos, el internacional y el constitucional, señalando en cada caso, en primer lugar, de forma sintética, la posición general de partida sobre la obligatoriedad de la reforma, y luego, de modo algo más extenso, la crítica que mantenemos al respecto.

\section{II.1. Plano internacional}

Las asociaciones de personas con discapacidad, muchos políticos y bastantes académicos no se han cansado de repetir que la derogación del artículo 3.1 b) y c) de la LOREG era una obligación jurídica una vez aprobada la Convención, en atención, en especial, a su artículo 29 sobre la participación en la vida política y pública, que obliga a los Estados Partes a asegurar «el derecho y la posibilidad de las personas con discapacidad a votar y ser elegidas» ${ }^{6}$. Elemento fundamental en la decantación de esta posición fue el Informe de 2011 sobre España del Comité de Derechos de las Personas con Discapacidad, creado por la propia Convención para favorecer su aplicación efectiva, que apuntó la necesidad de la modificación legislativa:

«El Comité recomienda que se revise toda la legislación pertinente para que todas las personas con discapacidad, independientemente de su deficiencia, de su condición

6 Vid., entre otros, Martínez-Pujalte, A. L. (2015). Derechos fundamentales y discapacidad, Madrid, Cinca, pp. 91-92; Pascual Planchuelo, V. C. (2016). «El derecho de voto de las personas con discapacidad y, en especial, de las personas con discapacidad psíquica o intelectual en Derecho Internacional. Su recepción en España». Revista Española de Discapacidad, 4 (1), pp. 114-115; y Rivas Vañó, A. (2018), «Discapacidad intelectual y derecho al sufragio: la inacción del Tribunal Constitucional español», en Caruso Fontán, $\mathrm{M}^{\mathrm{a}}$ V. y Pérez Alberdi, $\mathrm{M}^{\mathrm{a}} \mathrm{R}$. (dirs.), Diálogos judiciales en el sistema europeo de protección de derechos: una mirada multidisciplinar, Valencia, Tirant lo Blanch, pp. 276-279. 
jurídica o de su lugar de residencia, tengan derecho a votar y a participar en la vida pública en pie de igualdad con los demás. El Comité pide al Estado parte que modifique el artículo 3 de la Ley orgánica $\mathrm{N}^{\circ}$ 5/1985, que autoriza a los jueces a denegar el derecho de voto en virtud de decisiones adoptadas en cada caso particular. La modificación debe hacer que todas las personas con discapacidad tengan derecho a votar ${ }^{7}$.

Así lo recoge la propia exposición de motivos de la Ley Orgánica 2/2018, de 5 de diciembre, de reforma de la LOREG, que habla de que «garantizar la participación plena y efectiva en la sociedad de las personas con discapacidad se convierte en un elemento esencial para cumplir con los compromisos adquiridos internacionalmente por España» y que «a este respecto, el ejercicio del derecho de sufragio en igualdad de condiciones supone la máxima expresión de participación política de los miembros de una sociedad democrática»; recuerda que «el Comité sobre los derechos de las personas con discapacidad de Naciones Unidas, en el examen al que sometió a España» en 2011 «aprobó en sus observaciones finales» la recomendación de modificar la LOREG para ajustarla al artículo 29 de la Convención; y pone de manifiesto «el compromiso adquirido por el Estado español — con la ratificación de la Convención Internacional sobre los derechos de las personas con discapacidad- de garantizar el pleno y efectivo ejercicio de todos los derechos y libertades fundamentales de todas las personas con discapacidad $»^{8}$.

$\mathrm{Y}$ en este mismo sentido se produjeron muchas intervenciones parlamentarias durante su tramitación, como, por ejemplo, en el debate de toma en consideración en el Congreso de los Diputados, en donde se habló de que «la aprobación de esta ley era legalmente insoslayable», pues «la privación del derecho de sufragio ha venido en todo este tiempo vulnerando leyes y tratados internacionales, especialmente la Convención Internacional de Derechos de las Personas con Discapacidad, ratificada por España en 2008 y que forma parte desde esta fecha de nuestro ordenamiento interno», de «la necesidad de asumir el compromiso de España con la Convención Internacional sobre los Derechos de las Personas con Discapacidad, que refleja inequívocamente que ninguna persona, por motivos asociados a su discapacidad, pueda ser privada del

7 Punto 48 de las Observaciones finales del Comité de Derechos de las Personas con Discapacidad, aprobadas el 23 de septiembre de 2011, al Informe presentado por España con arreglo al artículo 35 de la Convención. CRPD/C/ESP/CO/1. Con anterioridad, en el punto 47, el Comité señala: «Preocupa al Comité que se pueda restringir el derecho al voto de las personas con discapacidad intelectual o psicosocial si la persona interesada ha sido privada de su capacidad jurídica o ha sido internada en una institución. Le inquieta además que la privación de ese derecho parezca ser la regla y no la excepción. El Comité lamenta la falta de información sobre el rigor de las normas en materia de prueba, sobre los motivos requeridos y sobre los criterios aplicados por los jueces para privar a las personas de su derecho de voto. El Comité observa con preocupación el número de personas con discapacidad a las que se ha denegado el derecho de voto».

${ }^{8}$ Y lo declara expresamente la propia Ley, que en el texto de la nueva disposición adicional octava señala que se dejan sin efecto las limitaciones del sufragio establecidas en las resoluciones judiciales a partir de la entrada en vigor de la Ley de modificación de la LOREG «para adaptarla a la Convención Internacional sobre los Derechos de las Personas con Discapacidad». 
derecho al voto» o de que «esta Convención es un tratado internacional que España ha ratificado y que, por tanto, hay que cumplirlo»?

No compartimos esta conclusión. A nuestro juicio, el artículo 29 de la Convención no entraña una prohibición absoluta de cualquier posibilidad de privar del sufragio a una persona con discapacidad sin entrar a considerar causas, requisitos y garantías y, por tanto, no obliga a los Estados Partes a derogar de plano las disposiciones que lo permiten en casos muy determinados y cumpliendo ciertas condiciones, como era el caso del artículo 3 de la LOREG antes de su modificación.

Para explicar este disenso hay que comenzar por poner de relieve el tenor literal del artículo 29 de la Convención, que dice así en la parte que nos interesa:

«Los Estados Partes garantizarán a las personas con discapacidad los derechos políticos y la posibilidad de gozar de ellos en igualdad de condiciones con las demás y se comprometerán a:

a) Asegurar que las personas con discapacidad puedan participar plena y efectivamente en la vida política y pública en igualdad de condiciones con las demás, directamente o a través de representantes libremente elegidos, incluidos el derecho y la posibilidad de las personas con discapacidad a votar y ser elegidas, entre otras formas mediante:

i) La garantía de que los procedimientos, instalaciones y materiales electorales sean adecuados, accesibles y fáciles de entender y utilizar;

ii) La protección del derecho de las personas con discapacidad a emitir su voto en secreto en elecciones y referéndum públicos sin intimidación, y a presentarse efectivamente como candidatas en las elecciones, ejercer cargos y desempeñar cualquier función pública a todos los niveles de gobierno, facilitando el uso de nuevas tecnologías y tecnologías de apoyo cuando proceda;

iii) La garantía de la libre expresión de la voluntad de las personas con discapacidad como electores y a este fin, cuando sea necesario y a petición de ellas, permitir que una persona de su elección les preste asistencia para votar» ${ }^{10}$.

La atenta lectura de este artículo permite observar en él varias prescripciones para los Estados Partes, articuladas en muy distinto nivel:

9 Las citas corresponden, respectivamente, a las intervenciones de la diputada de la Asamblea de Madrid Beatriz Gimeno Reinoso (Podemos), el diputado del Congreso de los Diputados Isidro M. Martínez Oblanca (Foro Asturias) y la diputada también del Congreso M ${ }^{a}$ Teresa Arévalo Caraballo (Unidos Podemos - En Común Podem - En Marea). Vid. Cortes Generales, Diario de Sesiones del Congreso de los Diputados, Pleno y Diputación Permanente, XII Legislatura, núm. 87, 7 de noviembre de 2017, pp. 6, 9 y 14.

10 El apartado b) del artículo 29 se ocupa, por su parte, de la participación en los asuntos públicos, y se centra en la constitución e incorporación a organizaciones representativa de sus intereses y en la participación en organizaciones y asociaciones no gubernamentales, incluidos los partidos políticos.

(C) UNED. Revista de Derecho Politico

N. ${ }^{\circ} 109$, septiembre-diciembre 2020, págs. 15-45 
- En primer lugar, se establece una obligación general de asegurar que las personas con discapacidad puedan participar plena y efectivamente en la vida política en igualdad de condiciones, incluidos el derecho y la posibilidad de votar.

- En segundo término, se prevé que ese aseguramiento ha de realizarse «entre otras formas» mediante tres garantías: la de que los procedimientos, instalaciones y materiales electorales sean adecuados, accesibles y fáciles de entender y utilizar, la del derecho de las personas con discapacidad a emitir su voto en secreto sin intimidación y la de la libre expresión de la voluntad de las personas con discapacidad como electores.

- Y, en tercer lugar, se establecen unas obligaciones concretas para hacer realidad estas dos últimas garantías en el voto de las personas con discapacidad: en relación con la garantía del voto secreto y sin intimidación, la de facilitar el uso de nuevas tecnologías y tecnologías de apoyo cuando proceda; y en relación con la libre expresión de su voluntad como electores, la de permitir que una persona de su elección les preste asistencia para votar cuando sea necesario y a petición de ellas.

Como se puede observar, la obligación general que se impone a los Estados de asegurar la participación plena y efectiva de las personas con discapacidad en la vida política en igualdad de condiciones, incluidos el derecho y la posibilidad de votar, está íntimamente unida, en la misma línea y sin separación alguna, a determinadas garantías (adecuación, accesibilidad y facilidad de entendimiento y uso de procedimientos, instalaciones y materiales, sufragio secreto, ausencia de intimidaciones, libre expresión de la voluntad electoral, apoyos tecnológicos y personales), lo que induce a pensar que la universalidad de goce o ejercicio del derecho de sufragio es una tendencia a conseguir con dichas garantías, más que un principio inexorable a imponer de forma independiente.

Adviértase, además, que entre las garantías que se citan no se encuentra, ni expresa ni tácitamente, la de la inserción incondicionada en el censo de electores, sin excepción alguna, de todas las personas con discapacidad. Y esto no parece un olvido, pues el artículo 29 es bastante detallado y, además, en el momento en que se aprobó la mayoría de los países contenían disposiciones que permitían excluir del sufragio, con mayor o menor extensión y garantías, a las personas con discapacidad intelectual o mental y no entendieron, por lo general, que hubiera que eliminarlas en todo caso y circunstancia ${ }^{11}$, sino más bien reformularlas en un sentido más restrictivo, individualizado y garantista.

Y dos observaciones más para completar la interpretación del artículo 29 de la Convención. Una, que esta disposición no se dirige específicamente a las personas con

11 Vid., por ejemplo, Consejo de Derecho Humanos (2011), Estudio temático preparado por la Oficina del Alto Comisionado de las Naciones Unidas para los Derechos Humanos de la ONU sobre la participación de las personas con discapacidad en la vida política y pública, A/HRC/19/36, puntos 38-41. 
discapacidad intelectual o mental, sino a todo el colectivo de la discapacidad, en su amplia heterogeneidad, lo que explica los términos genéricos con que se formula y la consiguiente posibilidad de admitir matizaciones en su despliegue. Y dos, y en conexión con lo que acabamos que apuntar, que el aseguramiento del «derecho y la posibilidad de las personas con discapacidad a votar» al que alude el precepto debe compatibilizarse necesariamente con el presupuesto participativo básico, ínsito en la naturaleza del derecho de sufragio, de tener la capacidad de autodeterminación política, es decir, de poder formar y expresar una voluntad política propia ${ }^{12}$; es más, ello está implícito en el núcleo de la norma, pues la indispensable garantía de «la libre expresión de la voluntad de las personas con discapacidad como electores» solo tiene sentido si dicha voluntad existe y es consciente y voluntaria.

Por otra parte, no es solo el argumento gramatical y lógico el que conduce a esta conclusión, es que tampoco la lectura del artículo 29 de la Convención en conexión con otros artículos de la misma lleva a otro resultado. Nos referimos a los artículos 1 (Propósito), 2 (Definiciones), 3 (Principios generales), 4 (Obligaciones generales), 5 (Igualdad y no discriminación) y 12 (Igual reconocimiento como personas ante la ley).

El precepto con más fondo y enjundia es este último, el 12, sobre igual reconocimiento como personas ante la ley, que, tras establecer que los Estados Partes reconocerán que las personas con discapacidad tiene capacidad jurídica en igualdad de condiciones con las demás en todos los aspectos de la vida y que adoptarán las medidas pertinentes para proporcionarles acceso al apoyo que puedan necesitar en el ejercicio de su capacidad jurídica, previene frente a los posibles abusos: prescribe que los Estados asegurarán que en todas las medidas relativas al ejercicio de la capacidad jurídica se proporcionen salvaguardias adecuadas y efectivas para impedir los abusos de conformidad con el derecho internacional en materia de derechos humanos, puntualizando que esas salvaguardias garantizarán que las medidas relativas al ejercicio de la capacidad jurídica respeten los derechos, la voluntad y las preferencias de la persona, que no haya conflicto de intereses ni influencia indebida, que sean proporcionales y adaptadas a las circunstancias de la persona, que se apliquen en el plazo más corto posible y que estén sujetas a exámenes periódicos por parte de una autoridad o un órgano judicial competente, independiente e imparcial.

Esta llamada de la Convención a hacer frente a los abusos nos lleva a plantear con toda lógica: ¿qué mejor aseguramiento frente a los mismos puede haber en ocasiones que excluir del proceso electoral a quien se acredita con todas las garantías que carece de entendimiento y voluntad para expresar una opinión política?

No resulta, por tanto, tan evidente, a nuestro juicio, esa pretendida incompatibilidad que muchos han visto entre la Convención, en especial el artículo 29, y las normas estatales que permiten privar del ejercicio del sufragio a las personas con discapacidad intelectual o mental bajo ciertas condiciones y garantías, como sucedía

12 Vid. Presno Linera, M. Á. (2003). El derecho de voto, Madrid, Tecnos, pp. 135-136 y 144. 
con el artículo 3 de la LOREG ${ }^{13}$. Todo lo contrario, consideramos que es muy forzado entenderlo así y que es más razonable considerar que el artículo 29 de la Convención lo que exige realmente es una política legislativa sumamente restrictiva en este terreno y coherente en todo momento con la naturaleza del derecho, es decir, que la privación del ejercicio del sufragio por razón de discapacidad intelectual o mental sea una medida excepcional que debe estar suficientemente motivada en cada caso y que solo procede cuando por el estado de la persona — privada de entendimiento y voluntad- no haya posibilidad, ni con la articulación de un sistema de apoyos, de un voto mínimamente consciente y libre.

Y ésta ha sido también, en buena medida, la opinión de los tribunales españoles. En primer lugar, de los tribunales ordinarios —en concreto de la jurisdicción civil-, que durante años han aplicado el artículo 3 de la LOREG sin preterirlo ante el artículo 29 de la Convención y sin plantear tampoco ninguna cuestión de inconstitucionali$\operatorname{dad}^{14}$. Ello incluye a su máxima instancia, el Tribunal Supremo, que ha señalado que la privación del sufragio por aplicación del artículo 3 de la LOREG es compatible con la Convención en la medida en que no es una consecuencia automática o necesaria del estado de discapacidad intelectual o mental de la persona y está rodeada de diversas garantías. Así, en una de sus últimas y más paradigmáticas sentencias sobre el tema, la 181/2016, de 17 de marzo, el Tribunal Supremo manifestó:

«El artículo 29 de la Convención (SSTS 24 de junio 2013, 1 de julio 2014, entre otras) garantiza a las personas con discapacidad los derechos políticos y la posibilidad de gozar de ellos en igualdad de condiciones y como corolario lógico ejercer el derecho de voto que se considera conveniente y beneficioso, mientras que el artículo 3.1 b y 2 de la Ley 5/85, de 19 de julio, del Régimen Electoral General, señala que los declarados incapaces en virtud de sentencia judicial firme quedarán privados del derecho de sufragio, siempre que la misma declare expresamente la incapacidad para su ejercicio, debiendo los Jueces o Tribunales que entiendan de los procedimientos de incapacitación o internamiento pronunciarse expresamente sobre la incapacidad para el ejercicio del sufragio. La pérdida del derecho de sufragio no es una consecuencia automática o necesaria de este estado, sino que es posible la incapacitación y la reserva al incapaz de este derecho pues una cosa es que una persona no pueda regirse por sí misma, ni administrar su patrimonio, y otra distinta que esté impedida para ejerci-

13 Sobre las dudas interpretativas vid. Barrat Esteve, J. (2017). «Discapacitados mentales y participación política: el derecho de sufragio», en Escobar Roca, G. (ed.), Ombudsman y colectivos en situación de vulnerabilidad. Actas del III Congreso Internacional del PRADPI, Valencia, Tirant lo Blanch, p. 159; Vyhnánek, L. (2014). «Mental disability and the right to vote in Europe: a few notes on the recents devolement». International Journal of Disability Studies, vol. 7, núm. 1, p. 121; y Gálvez Muñoz, L. A. (2019). «Los pilares de la reforma electoral de 2018 para garantizar el derecho de sufragio de todas las personas con discapacidad». Corts. Anuario de Derecho Parlamentario, núm. 32, p. 79.

14 Esta actitud de los tribunales civiles ha sido criticada por algunos autores, como Cuenca Gómez, P. (2018). «El derecho de voto de las personas con discapacidad intelectual y psicosocial. La adaptación de la legislación electoral española a la Convención Internacional de Derechos de las Personas con Discapacidad». Derechos y libertades, núm. 38, pp. 192-193. 
tarlo correctamente. Es el Juez que conoce del proceso a quien corresponde analizar y valorar la situación de la persona sometida a su consideración y pronunciarse sobre la conveniencia de negar el ejercicio de este derecho fundamental, que es regla y no excepción, a quien puede hacerlo no obstante su situación personal. La decisión de privación del derecho de sufragio activo es por tanto legalmente posible y compatible con la Convención de Nueva York, sin perjuicio de que para la eventual adopción de tal medida sea preciso examinar de forma concreta y particularizada las circunstancias e intereses concurrentes, evitando todo automatismo, incompatible con los derechos fundamentales en juego, para calibrar la necesidad de una medida...» ${ }^{15}$.

Y, en segundo lugar, del Tribunal Constitucional, que ha respaldado la visión del Tribunal Supremo ante la invocación para interpretar el derecho de sufragio del artículo 23 CE con arreglo a la Convención, de acuerdo con el artículo 10.2 CE. Lo ha hecho en el Auto 196/2016, de 28 de noviembre, que desestima el recurso de súplica presentado por el Ministerio Fiscal contra la inadmisión del recurso de amparo interpuesto contra dicha Sentencia del Supremo por los tutores de la persona afectada ${ }^{16}$. En esta resolución el Tribunal de Garantías proporciona una respuesta algo más elaborada y que se centra en señalar el diferente ámbito y finalidad del artículo 29 de la Convención y el artículo 3 de la LOREG, la clave a su juicio para su correcta conciliación:

«Respecto de la invocada interpretación del art. 23 CE conforme a la Convención sobre los derechos de las personas con discapacidad... y, singularmente, conforme a su artículo 29, debe tenerse en cuenta, en primer término, la distinción entre "discapacidad" en el sentido de la Convención, concepto muy amplio en que tiene cabida cualquier "deficiencia física, mental, intelectual o sensorial a largo plazo" que pueda impedir la efectiva igualdad (art. 1 de la citada Convención), de "incapacidad" en el sentido definido por el Código civil (CC) — "enfermedades o deficiencias persistentes de carácter físico o psíquico, que impidan a la persona gobernarse por sí misma” (art. 200 CC)—, y concretado respecto del ejercicio del derecho que nos ocupa en el art. 3 LOREG. En este último se trata de la capacidad de la persona — de cada personapara emitir el voto como "libre expresión de la voluntad del elector", lo que también garantiza la Convención [art. 29 a) iii)], cuya finalidad se inscribe más bien, en línea con el mandato contenido en el art. 9.2 CE, de remover los obstáculos que impidan o dificulten la emisión del voto libre, secreto y sin intimidación [apartado a) II y II

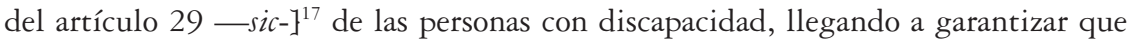
"cuando sea necesario y a petición de ellas" que "una persona de su elección les preste asistencia para votar". Partiendo de este ámbito de aplicación y finalidad diferentes, las razones apuntadas por los recurrentes no siembran duda sobre la compatibilidad del art. 29 de la Convención internacional sobre los derechos de las personas con dis-

15 FJ segundo.

16 Sobre este auto vid. Gómez-Riesco Tabernero De Paz, J. (2017). «La privación del ejercicio de derecho de sufragio activo de las personas con la capacidad modificada judicialmente: comentario al Auto del Tribunal Constitucional 196/2016, de 28 de noviembre». Derecho privado y Constitución, núm. 31; y Gálvez Muñoz, L. A. (2019). «Los pilares de...», op. cit., pp. 101-105.

17 Es una errata del Auto. Son los puntos II y III del apartado a) del artículo 29 de la Convención. 
capacidad y el art. 3.1 b) LOREG, tal y como han sido conciliados en la más reciente jurisprudencia del Tribunal Supremo... ${ }^{18}$

Esta posición es, además, compartida en su esencia por dos de los órganos más importantes establecidos en la esfera internacional para la defensa de los derechos humanos: la Comisión de Derechos Humanos de la ONU ${ }^{19}$ y el Tribunal Europeo de Derechos Humanos ${ }^{20}$. Si bien no se han pronunciado expresamente sobre la interpretación del artículo 29 de la Convención, ni mucho menos sobre el artículo 3 de la LOREG, lo cierto es que, vigente la Convención y teniéndola en cuenta ${ }^{21}$, han considerado legítima la privación del sufragio por razón de discapacidad intelectual o mental siempre que se haga de forma individual y se guarde una necesaria relación de proporcionalidad.

Finalmente, interesa poner de relieve, porque quizás ha habido confusión sobre ello, que las observaciones realizadas por el Comité de Derechos de las Personas con Discapacidad no son obligatorias o vinculantes para los Estados Partes. Este Comité no es un órgano jurisdiccional, sino un órgano técnico en materia de discapacidad, formado por expertos de muy diversa formación académica, no solo juristas, y que fue creado por la Convención para facilitar su aplicación efectiva por medio de sus sugerencias y recomendaciones ${ }^{22}$.

El Comité de Derechos de las Personas con Discapacidad ha entendido, ciertamente, que existe una incompatibilidad entre el artículo 29 de la Convención y toda posibilidad de privación del sufragio a las personas con discapacidad intelectual ${ }^{23}, y$ la suya es, sin duda, una opinión muy cualificada, pero no pasa de ser una recomendación. De hecho, muchos Estados no la han seguido, y, como hemos visto, tampoco importantes organismos internacionales de defensa de los derechos humanos ${ }^{24}$.

$18 \mathrm{Fj}$ tercero.

19 Vid. las Observaciones finales de la Comisión de Derechos Humanos de la ONU sobre la situación de los derechos civiles y políticos en Belice, aprobadas en su sesión de 26 de marzo de 2013 (A/ HRC/19/36).

20 Vid. la Sentencia del Tribunal Europeo de Derechos Humanos Alajos Kiss vs. Hungría, de 20 de mayo de 2010. Sobre la misma vid. Bariffi, F. J. (2013), «Corte Europea de Derechos Humanos: Ejercicio del derecho al voto de personas sujetas a un régimen de tutela (Caso Alajos Kiss vs. Hungría)», en Bariffi, F. J. (coord.), Práctica clínica y litigación estratégica en discapacidad y Derechos Humanos: algunas experiencias de Iberoamérica, Madrid, Dykinson, pp. 457-462.

21 De los documentos citados vid., en concreto, los puntos 5 y 24, segundo párrafo, de las Observaciones finales de la Comisión de Derechos Humanos, y el punto 14 de la Sentencia del Tribunal Europeo de Derechos Humanos.

22 Vid. los artículos 34 a 39 de la Convención, así como su Protocolo Facultativo.

23 El Comité lo ha sostenido así de forma reiterada y no solo en el Informe citado sobre España de 2011. Vid., por ejemplo, su Informe de 9 de septiembre de 2013 sobre la Comunicación 4/2011 presentada por varias personas con discapacidad de nacionalidad húngara (CRPD/C/10/D/4/2011) y la Observación General número 6, de 2018, sobre la igualdad y la no discriminación consagradas en el artículo 5 de la Convención.

24 Vid. European Union Agency For Fundamental Rights (2019). Who will (not) get to vote in the 2019 European Parliament elections? Developments in the right to vote of people deprived of legal capacity in EU 


\section{II.2. Plano constitucional}

Además del argumento de la vinculación internacional, de carácter preferentemente formal, la eliminación de la posibilidad de privar del sufragio por falta de capacidad electoral que ha efectuado la Ley Orgánica 2/2018, de 5 de diciembre, de reforma de la LOREG, se apoya en una concreta y variada fundamentación material de naturaleza constitucional, aunque con engarce internacional, proporcionada por especialistas $^{25}$, organizaciones ${ }^{26} \mathrm{y}$ asociaciones de personas con discapacidad ${ }^{27}$. Es ella realmente la que ha llevado a nuestro país, como a otros muchos, a decidirse por reformar su legislación.

¿En qué consiste esta fundamentación? En este sentido se ha señalado la necesidad de poner término a la lesión que la norma en cuestión producía sobre varios principios constitucionales conectados a derechos fundamentales y leídos a la luz de la Convención. Básicamente: el principio de sufragio universal previsto en el artículo 23.1 de la $\mathrm{CE}$, que reconoce este derecho a todos «los ciudadanos», sin prever excepción alguna; el principio de igualdad ante la ley y no discriminación reconocido en el artículo 14 de la CE, que proscribe la discriminación por determinadas circunstancias entre las que cabe incluir la discapacidad, aunque no se cite, y que impediría que una persona pueda ser sometidas de manera específica, y por razón de su discapacidad, a una evaluación de su capacidad para ejercer un derecho; y el principio de protección o favorecimiento de las personas con discapacidad proclamado en el artículo 49 de la $\mathrm{CE}$, que exige a los poderes públicos ampararlas en el disfrute de sus derechos, como el de participación, no restringirlos.

La exposición de motivos de la Ley de reforma, a diferencia de lo sucedido con el argumento internacional, como vimos, apenas se ha detenido en la cuestión de la fundamentación material. Solo alude, y de forma limitada, al choque del artículo 3 «con el principio de igualdad ante la ley consagrado en nuestra Constitución». Sí hubo, en cambio, abundantes referencias a esta cuestión durante el proceso de tramitación parlamentaria, tanto en la Asamblea de Madrid, de donde partió la iniciativa, como en el Congreso de los Diputados y el Senado, que la debatieron y aprobaron. Valga por todas, la intervención de la diputada Gimeno Reinoso, del Grupo Parlamentario de Podemos, en el debate de toma en consideración de la proposición en la Asamblea de Madrid, en el inicio mismo de la reforma:

members States, Luxemburgo, FRA, 2019; y Barrat Esteve, J. (2017). «Discapacitados mentales...», op. cit., pp. 160-162.

25 Vid., entre otros muchos, Martínez-Pujalte, A. L. (2015). Derechos fundamentales..., op. cit., pp. 86 y ss.; Cuenca Gómez, P. (2018). «El derecho de...», op. cit.; y Beckman, L. (2009).

26 Es el caso, por ejemplo, del Comité de Derechos de las Personas con Discapacidad, con los diversos informes que ha realizado, como la Observación general número 1, de 2014, sobre el artículo 12 de la Convención, relativo al igual reconocimiento como persona ante la ley (CRPD(C7GC/1).

27 De manera muy destacada el CERMI, responsable, entre otros documentos, de la propuesta de proposición de ley orgánica de modificación de la LOREG origen de Ley Orgánica 2/2018 que estamos examinando.

(C) UNED. Revista de Derecho Politico

N. ${ }^{\circ} 109$, septiembre-diciembre 2020, págs. 15-45 
«El artículo 29... deja clarísimo el derecho de estas personas a participar en la vida política mediante el sufragio activo y pasivo. Además, hay que poner este artículo 29 en relación con el artículo 23.1 de la Constitución, relativo al derecho al sufragio como uno de los derechos políticos esenciales para que se dé esta participación plena. También habría que ponerlo, desde luego, en relación con el artículo 14, que establece la no discriminación, y finalmente, con el 49, que impone a los poderes públicos, y entre ellos al Poder Judicial, la obligación de amparar especialmente a las personas con discapacidad para el disfrute de los derechos que el Título I otorga a todos los ciudadanos.

Este artículo 49, precisamente, muy a menudo, demasiado a menudo, ha sido aplicado de una manera perversa, diríamos, en tanto que se ha entendido que retirar el derecho al sufragio era una manera de proteger los derechos de estas personas, y así se ha venido haciendo, como digo, demasiado a menudo en los procesos de incapacitación. La incapacitación judicial con vistas a la protección de estas personas no puede constituirse en un motivo de exclusión para gozar plenamente de los derechos políticos...

En estos procesos de incapacitación los jueces han venido pidiendo una especie de requisito previo que no se solicita a ninguna otra persona para conservar el derecho de sufragio, lo que constituye una discriminación evidente. A ningún ciudadano de este país se nos exige ningún criterio o requisito para saber por qué votamos, cómo lo hacemos, con qué entendimiento, con qué conocimiento, y ni siquiera hace falta, como es lógico, saber leer o escribir. El sufragio universal es un derecho inalienable y personal, todos tenemos derecho al mismo, sin requisito alguno, excepto en estos casos las personas con discapacidad. Exigir un determinado conocimiento para poder votar es poner el listón más alto para estas personas, lo cual es una clarísima discriminación» ${ }^{28}$.

Nuestra opinión es muy diferente, pues consideramos que la posibilidad de privar del ejercicio del derecho de sufragio a las personas sometidas a un proceso de modificación de capacidad o internamiento no vulnera ninguno de los principios constitucionales mencionados y, por tanto, que no existe incompatibilidad alguna entre el artículo 3 de la LOREG, en la redacción anterior a la reforma, que permitía dicha privación, y la CE, que proclama tales principios en su Título I. Expondremos brevemente el porqué de nuestra posición.

a) En primer lugar, no se vulnera, a nuestro juicio, el principio de universalidad del sufragio proclamado en el artículo 23.1 de la $\mathrm{CE}^{29}$. Es cierto que el sufragio universal se reconoce en este artículo de forma general e irrestricta a los ciudadanos, sin establecer limitación o excepción alguna o llamadas al legislador, pero ello no autoriza a considerar que cualquier limitación del derecho de sufragio, como es el caso de la que preveía el artículo 3 de la LOREG, lo contravine e incurre en inconstitu-

28 Diario de Sesiones de la Asamblea de Madrid, X Legislatura, núm. 341, 15 de diciembre de 2016, pp. 20162-20163.

29 En sentido contrario vid., entre otros, Cuenca Gómez, P. (2018). «El derecho de...», op. cit., pp. 185-186. Esta crítica estuve presente, por otra parte, en los diferentes recursos que dieron lugar al ATC 196/2016, de 28 de noviembre. 
cionalidad, pues hay que tener presente el sentido y alcance de las categorías jurídicas implicadas.

Más allá del argumento formal de que la expresión «ciudadanos» no ha sido objeto de definición constitucional alguna ${ }^{30}$, son dos los argumentos básicos a emplear desde esta perspectiva.

- Uno, el derecho de sufragio es un derecho de configuración legal y, en cuanto tal, la determinación de sus elementos estructurales corresponde al legislador ${ }^{31}$, siempre, obviamente, con el límite de la Constitución y, en particular, de las exigencias generales de intervención en los derechos fundamentales de los ciudadanos ${ }^{32}$. Esta intervención legislativa incluye las condiciones que afectan a la titularidad y ejercicio del derecho, como ha reconocido expresamente el Tribunal Constitucional ${ }^{33}$ y admite, además, el Derecho internacional ${ }^{34}$.

- Y dos, el derecho de sufragio exige, como parte de su misma delimitación natural o configuración esencial, la capacidad de autodeterminación política o electoral por parte de quienes lo ejercen, es decir, de poder formar una voluntad electoral consciente y libre, pues en caso contrario, nos encontraríamos ante un ejercicio meramente formal del derecho, desconectado de su finalidad y carente de sentido. En consecuencia, la autodeterminación política es un presupuesto del derecho de sufragio y, por tanto, de su carácter universal, más que una limitación en sentido estricto del mismo ${ }^{35}$.

b) En segundo término, tampoco compartimos la idea de que el artículo 3 de la LOREG, en su anterior redacción, vulnere el principio de igualdad y no discriminación reconocido en el artículo 14 de la CE, en conexión con diversos preceptos de textos internacionales (como los artículos 5 y 12 de la Convención de 2006), por

30 Sobre el concepto de ciudadano y su conexión con la titularidad de los derechos de participación vid. Aláez Corral, B. (2006). Nacionalidad, ciudadanía y democracia: ¿a quién pertenece la Constitución de 1978?, Madrid, Centro de Estudios Políticos y Constitucionales; y Pérez Alberdi, Ma R. (2013). El derecho fundamental a participar en los asuntos públicos. Madrid, Congreso de los Diputados, pp. 72 y ss.

31 Sobre esta dimensión del derecho de sufragio vid. Solozábal Echavarría, J. J. (2004). «La actuación efectiva del proceso electoral y sus posibilidades», Revista Española de Derecho Constitucional, núm. 70, p. 130. Vid. también Azpitarte Sánchez, M. (2002). «La dimensión constitucional del procedimiento electoral», Teoría y Realidad Constitucional, núms. 10-11, segundo semestre de 2002-primer semestre de 2003, pp. 425 y ss.; y Pérez Alberdi, M R. (2013). El derecho fundamental..., op. cit., pp. 109 y ss.

32 Así, fundamentalmente, la integridad del contenido esencial del derecho afectado, el tipo de ley, su calidad, la persecución de un fin legítimo y la conformidad con el principio de proporcionalidad.

33 Así, STC 153/2014, de 25 de noviembre, FJs tercero y cuarto.

34 Vid. en este sentido el artículo 25 del Pacto Internacional de Derechos Civiles y Políticos de 1966, así como la Observación general 25, de 1996, del Comité de Derechos Humanos, cuya vigencia ha sido reiterada en 2013 por el propio Comité.

35 Vid. Presno Linera, M. Á. (2003). El derecho de..., op. cit., pp. 135-y ss.; y Gálvez Muñoz, L. A. (2014). «El derecho de sufragio en el siglo XX», Derechos y Libertades, núm. 31, pp. 173-174.

(C) UNED. Revista de Derecho Politico

N. ${ }^{\circ} 109$, septiembre-diciembre 2020, págs. 15-45 
considerarse, básicamente, que someter a determinadas personas con discapacidad a un examen de capacidad electoral que no se exige al resto de la población entraña una discriminación de grupo social proscrita especialmente por la Constitución.

Es quizás éste el argumento más relevante de los alegados por los defensores de la reforma ${ }^{36}$, pero creemos que hay elementos suficientes y sólidos para cuestionarlo y poder descartarlo. Básicamente, y reduciendo lo máximo posible los términos del razonamiento, los argumentos son los cuatro siguientes:

1. La capacidad electoral o de autodeterminación política es, como hemos visto en el punto anterior, un elemento esencial del derecho de sufragio, y, como tal, su concurrencia es exigible siempre en todo elector. Cuestión distinta y secundaria es la de la regulación de su constatación o cumplimiento. En este ámbito, el ordenamiento había sido resolutivo y práctico: con la mayoría de edad establece la presunción de su existencia, pero, a la vez, preveía un mecanismo específico para ponerla en cuestión, el regulado precisamente en el artículo 3 de la LOREG, que se reviste de la garantía judicial y se activa por la posible concurrencia de una enfermedad o deficiencia persistente o de una crisis mental que impiden la autogobernación de la persona ${ }^{37}$. Ahora bien, y esto es lo interesante, dicha presunción, conforme a su propia naturaleza, puede cuestionarse respecto de cualquier elector en el momento de expresión del sufragio, si se advierte su falta de conciencia, voluntad o libertad, aunque para ello no se haya establecido en la ley un mecanismo concreto de actuación, lo que dificulta enormemente su puesta en marcha, aunque no la impide $^{38}$.

2. El antiguo artículo 3 de la LOREG no priva del ejercicio del derecho de sufragio a las personas con discapacidad en general o a aquellas que adolecen de discapacidad intelectual o mental en particular, ni establece tampoco un sistema de valoración de la capacidad de estas personas para votar, algo que, sin duda, sí sería discriminatorio ${ }^{39}$. Nada más lejos de la realidad. Lo que hace el precepto es mucho más limitado, específico y, desde luego, pro-

36 Vid., por ejemplo, Cuenca Gómez, P. (2018). «El derecho de...», op. cit., pp. 196-200; y Fishkin, J. (2011). «Equal Citizenship and the Individual Right to Vote», Indiana Law Journal, vol. 86, 2011, pp. 1353 y ss. El argumento ha sido ampliamente tratado también por el Comité de Derechos de las Personas con Discapacidad; por ejemplo, en el Informe de 9 de septiembre de 2013 sobre la Comunicación 4/2011 presentada por varios ciudadanos húngaros (CRPD/C/10/D/4/2011), y en la Observación General número 6, de 2018, sobre la igualdad y la no discriminación consagradas en el artículo 5 de la Convención.

37 Sobre el concepto de autogobierno vid. la STS, Sala Civil, 341/2014, de 1 de julio, FJ. Sexto.

38 En la actualidad, tras la reforma de la LOREG que estamos estudiando, la Junta Electoral Central sí ha dictado criterios interpretativos para ordenar la cuestión. Vid. la Instrucción de la Junta Electoral Central 7/2019, de 18 de marzo, sobre aplicación de la modificación de la LOREG llevada a cabo por la Ley Orgánica 2/2018, de 5 de diciembre, en especial su punto segundo, párrafo dos.

39 Vid. la Sentencia del Tribunal Europeo de Derechos Humanos de 20 de mayo de 2010, caso Alajos Kiss contra Hungría, puntos 42 y 44. 
porcionado: permite al juez que conoce de un proceso de modificación de capacidad o internamiento psiquiátrico de una persona concreta — puesto en marcha por quien está legitimado para ello y con una mínima base fáctica de falta de autogobernación personal- valorar de forma individual, y con todas las garantías de prueba, contradicción y recurso, su capacidad para ejercer el derecho de sufragio ${ }^{40}$.

3. Este examen de la capacidad electoral de la persona afectada es, por otra parte, coherente con la situación de base que la misma puede padecer (una enfermedad o deficiencia persistente o una crisis mental que impiden la autogobernación) y con el mecanismo procesal puesto en marcha (el de modificación de capacidad o de internamiento psiquiátrico). Dicho de otro modo: lo que hacía el artículo 3 de la LOREG es únicamente concretar para el derecho de sufragio lo que la legislación civil predica con carácter general para las personas que se encuentran en esta particular situación: el examen de la persona para precisar su situación jurídica con arreglo a las concretas circunstancias en que se halla. La valoración de la capacidad de voto es, pues, una entre otras muchas de las actuaciones a realizar por el juez. Y hay que precisar que la previsible reforma de los procesos de «modificación de capacidad»

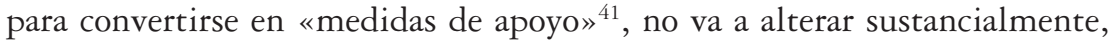
lo manifestado, más allá del cambio de perspectiva de poner formalmente en el centro el apoyo a la persona con problemas de autodeterminación o de capacidad de autogobierno.

4. Finalmente, es importante precisar que estos procesos no son en sí mismos discriminatorios, como tampoco contrarios a la Convención de 2006, pues se justifican por la propia situación de la persona, que presenta características específicas y propias. Como ha dicho el Tribunal Supremo, la razón se encuentra en que «el término de comparación es diferente», pues estas personas, frente al resto de población en general, «por sus condiciones no pueden gobernarse por sí mismas», por lo que la adopción de medidas específicas «está justificada dada la necesidad de protección de la persona por su falta de entendimiento y voluntad» ${ }^{42}$.

c) En tercer lugar, rechazamos también el argumento de que el derogado artículo 3 de la LOREG, al permitir la restricción del sufragio a las personas sometidas a un proceso de modificación de capacidad o de internamiento, por razón de incapacidad para su ejercicio, es contrario al principio de protección de las personas con dis-

40 Vid. los artículos 199 y ss. del Código Civil y 756 y ss. de la Ley de Enjuiciamiento Civil.

41 Vid. el Anteproyecto de ley por el que se reforma la legislación civil y procesal en materia de discapacidad aprobado por el Gobierno en septiembre de 2018, en la XII legislatura, concluida el 5 de marzo de 2019, y del que se espera una próxima reactivación.

42 Vid. la STS, Sala Civil, 282/2009, de 29 de abril, FJ quinto. 
capacidad que establece el artículo 49 de la $\mathrm{CE}^{43}$. Recordemos que este precepto, situado en el capítulo III del Título I, impone a los poderes públicos la obligación de realizar una «política de previsión, tratamiento, rehabilitación e integración» y de ampararles especialmente «para el disfrute de los derechos que este Título otorga a todos los ciudadanos» y se halla en sintonía con el espíritu inclusivo e igualitario de la Convención de $2006^{44}$.

Son varios los motivos que cabe sostener para rechazar esta crítica al viejo artículo 3 de la LOREG y defender su plena compatibilidad con el artículo 49 de la CE, en conexión con la Convención. Son, sucintamente expuestos, los siguientes:

1. No deben confundirse la naturaleza y alcance, e incluso los destinarios, del artículo 49 de la CE y del artículo 3 de la LOREG. La primera es una norma genérica que establece la finalidad integradora que ha de inspirar la política general de los poderes públicos sobre el conjunto heterogéneo de las personas con discapacidad, mientras que la segunda es una norma específica destinada a evaluar la capacidad para ejercer el derecho de sufragio y que opera exclusivamente en relación con aquellas personas que, por la discapacidad intelectual o mental que presentan, son sometidas a un proceso de modificación de capacidad o de internamiento psiquiátrico.

2. El artículo 3 de la LOREG operaba, por lo demás, en el límite de las políticas de integración de las que habla el artículo 49 de la CE. Si el artículo 3 se interpreta de forma adecuada, en conexión con el artículo 49 de la CE -algo que, lamentablemente, no siempre sucedía en la práctica judicial ${ }^{45}$ la privación del ejercicio sufragio solo puede decretarse por el juez de forma excepcional, cuando no exista ninguna forma eficaz de superar la incapacidad electoral, es decir, en aquellos casos en que no quepa establecer medidas de apoyo al elector que permitan el ejercicio del voto con un mínimo entendimiento y voluntad ${ }^{46}$.

43 Vid. Díaz Alabart, S. (2012). «El derecho de sufragio de las personas con discapacidad. La visión civilista», Revista de Derecho Privado, núm. 1, pp. 13-15; Martínez-Pujalte, A.-L. (2016). «Derechos en conflicto, conflicto de derechos: principales fricciones entre la Convención Internacional sobre los Derechos de las Personas con Discapacidad y la legislación nacional española», en Pérez Bueno, L.C. y Lorenzo García, R. de (dirs.), La Convención Internacional sobre los Derechos de las Personas con Discapacidad: 20062016 una década de vigencia (149-186), Madrid, Cinca, p. 181; y Cuenca Gómez, P. (2018). «El derecho de...», op. cit., pp. 196-197. Vid. También el recurso de nulidad de actuaciones presentado por la Fiscalía General del Tribunal Supremo el 11 de abril de 2016 contra la Sentencia del Tribunal Supremo de 17 de marzo de 2016.

44 Ésta se basa, entre otros, en los principios de accesibilidad, participación, inclusión, igualdad y autonomía en la toma de decisiones por parte de las personas con discapacidad.

45 Sobre la práctica judicial española anterior a la Convención vid. García Roca, J. (2007). «Declaración de incapacidad y privación del derecho de sufragio activo y pasivo», en Serrano García, I. (coord.), La protección jurídica del discapacitado. II Congreso Regional, Valencia, Tirant lo Blanch, pp. 183-187; y sobre la posterior Pascual Planchuelo, V. C. (2016). «El derecho de...», op. cit., pp. 117-118.

46 Vid. la STS, Sala Civil, 421/2013, de 24 de junio, FJ segundo. 
3. Finalmente, hay que tener en cuenta que el ejercicio del derecho de voto en estas circunstancias de falta absoluta de autodeterminación política no aportaría tampoco ningún beneficio efectivo a la persona afectada. Y es que si la persona se encuentra en un estado de falta de capacidad para formar y manifestar una decisión política y no es consciente del papel del derecho de sufragio, difícilmente su ejercicio tendrá repercusión alguna en su esfera personal y social.

En definitiva, creemos que ha quedado acreditada la compatibilidad del anterior artículo 3 de la LOREG con la CE y, por tanto, la debilidad del argumento de la necesidad de la reforma de la LOREG por exigencias constitucionales. No hay violación ni del principio-derecho de sufragio universal, ni del de igualdad y no discriminación, ni tampoco del de protección de las personas con discapacidad.

Y tampoco el Tribunal Constitucional había encontrado reproche alguno de inconstitucionalidad en el precepto, si bien empleando una argumentación muy limitada, propia de un auto de inadmisión de un recurso de amparo. Se trata del Auto 196/2016, de 28 de diciembre, ya citado, en el que, por un lado, rechaza la violación del modelo constitucional de sufragio universal, por tratarse de «un derecho fundamental de configuración legal» ${ }^{47}$, y, por otro, considera que no se discrimina a las personas con discapacidad, «dada la concreta disfuncionalidad que padecen y que se proyecta sobre su capacidad intelectiva y volitiva respecto del ejercicio del derecho de voto» ${ }^{48}$.

\section{III.- LA INJUSTA DESVALORACIÓN DEL ARTÍCULO 3 DE LA LOREG OBJETO DE LA REFORMA}

El segundo elemento de crítica que, a nuestro juicio, cabe sostener frente a la reforma electoral de 2018 es el de que la misma supone una injusta desvaloración del aporte del antiguo artículo 3 de la LOREG al sistema constitucional. Esta crítica está muy vinculada a la anterior, pero va un poco más allá en la argumentación: no es sólo que la eliminación de la posibilidad de privar del ejercicio de sufragio en los procesos de modificación de capacidad o internamiento psiquiátrico no fuera obligada por exigencias internacionales y constitucionales, como hemos visto, es que, además, esta previsión cumplía un relevante papel en el sistema, en términos de protección de derechos y bienes constitucionales de notable valor, por lo que su supresión resulta constitucionalmente negativa y disfuncional.

Veamos la argumentación en sus fases lógicas y sucesivas de finalidad constitucional, coherencia interna y necesidad o indispensabilidad. Seremos en esta tarea particularmente breves, pues buena parte de los elementos a resaltar ya nos son cono-

47 FJ segundo.

48 FJ tercero.

(C) UNED. Revista de Derecho Politico

N. ${ }^{\circ} 109$, septiembre-diciembre 2020, págs. 15-45 
cidos. Se trata ahora, simplemente, de seleccionarlos, estructurarlos y enfocarlos convenientemente a fin de dar cuenta de la funcionalidad que tiene el precepto para el sistema político.

\section{III.1. Finalidad constitucionalmente relevante}

La finalidad que se perseguía con el artículo 3 de la LOREG es de la máxima relevancia, pues opera en el propio orden de la constitucionalidad y no solo en el de su mera compatibilidad. Consiste, en concreto, en la protección o realización de dos bienes constitucionales de indudable valor, que se encuentran en la misma base de nuestro Estado Social y Democrático de Derecho ${ }^{49}$. Así:

a) En primer lugar, y de forma principal y manifiesta, el principio de integridad del proceso electoral, imperfectamente consagrado en el artículo 23.1 de la $\mathrm{CE}$ en conexión con el artículo 1 -mejor en documentos internacionales ${ }^{50}$-, pero que, en cualquier caso, exige que la participación de los electores sea consciente, libre y voluntaria, con un conocimiento mínimo de su significado y sin manipulaciones, resultado, por tanto, de su autodeterminación política. Es un principio basilar de unas elecciones auténticamente democráticas, pues votar con libertad, en el sentido amplio al que nos referimos, es la única forma de poder conocer de forma genuina, sin distorsiones, la voluntad del pueblo, y que las elecciones y, por tanto, la democracia, tengan valor real.

b) En segundo lugar, de un modo menos visible, el principio de protección de las personas con discapacidad, previsto en el artículo 49 de la CE, ya conocido, que, en interés de las personas afectadas y del mantenimiento de los propios valores esenciales de la sociedad, exige evitar su manipulación, que se las pueda utilizar como meros instrumentos de terceros, lesionando con ello su dignidad personal. El artículo 49 de la CE, como principio rector de la política social de los poderes públicos, no solo legitima y demanda la articulación de medidas de acción positiva en favor de las personas con discapacidad para favorecer su autonomía y tratar de lograr su plena inclusión en la sociedad, sino que también reclama medidas de protección en sentido es-

49 Sobre los fines de la norma vid., fundamentalmente, Presno Linera, M. Á. (2003). El derecho de..., op. cit., pp. 135 y ss. (también en Presno Linera, M. Á. (2011). El derecho al voto: un derecho político fundamental, p. 33 y ss., disponible en http://presnolinera.wordpress.com/elderechodevotounderechopolíticofundamental.pdf); Díaz Alabart, S. (2012). «El derecho de...», op. cit., pp. 9-10; Cuenca Gómez, P. (2018). «El derecho de...», op. cit., pp. 175 y ss.; y Pérez Alberdi, Ma R. (2019). «Los derechos de participación política de las personas con discapacidad». Lex Social. Revista Jurídica de los derechos sociales, vol. 9, núm. 1, pp. 101-103.

5o Así., por ejemplo, el artículo 25 b) del Pacto Internacional de Derechos Civiles y Políticos de 1966, que habla del derecho a «votar y ser elegidos en elecciones periódicas, auténticas, realizadas por sufragio universal e igual y por voto secreto que garantice la libre expresión de la voluntad de los electores» 
tricto de las mismas, en razón, precisamente, de su misma vulnerabilidad ${ }^{51}$; y es que a veces, para proteger, resulta preciso restringir la esfera de libertad de la persona.

Se aúnan así en el artículo 3 de la LOREG, como en pocas ocasiones, los intereses particulares y públicos, poniéndose de relieve la compleja naturaleza de los derechos fundamentales: de un lado, el interés particular de las concretas personas afectadas, sin la más mínima capacidad de conocimiento y decisión, de no ser utilizadas con fines espurios por parte de terceros, y, de otro lado, el interés general de la sociedad, tanto en garantizar la integridad del proceso electoral, como en defender la dignidad de sus miembros más vulnerables, como base del sistema de libertades. Se rompe con ello el esquema habitual de contraposición entre interés particular (régimen de libertad) e interés público (límites), lo que resalta el alcance de la norma ${ }^{52}$.

La jurisprudencia no se ha prodigado en el relato de estas finalidades. Por ello, tiene interés la Sentencia del Tribunal Supremo 181/2016, de 17 de marzo, que alude de forma conjunta, aunque algo genérica, a los mismos:

«Es una medida dirigida a proteger los intereses del incapaz y el propio interés general de que la participación electoral se realice de forma libre y con un nivel de conocimiento mínimo respecto del hecho de votar y de la decisión adoptada» ${ }^{53}$.

Finalmente, es importante advertir que el Tribunal Europeo de Derechos Humanos, en el caso Alajos Kiss contra Hungría de 20 de mayo de 2010, ya citado, ha admitido como legítimo el objetivo de «asegurar que solamente los ciudadanos capaces de evaluar las consecuencias de sus decisiones y de tomar decisiones conscientes y juiciosas debieran participar en los asuntos públicos» ${ }^{54}$. El Tribunal censura en el caso la «la restricción automática y global del derecho de voto de todos aquellos que están bajo tutela judicial», pero, en base a la legitimidad del objetivo, admite la posibilidad de una «evaluación judicial individual» para privar del ejercicio del sufragio, siempre que la misma se ajuste al principio de proporcionalidad ${ }^{55}$.

\section{III.2. Idoneidad, necesidad y proporcionalidad}

Ha quedado claro, pues, que el anterior artículo 3 de la LOREG tenía un fin relevante en términos constitucionales, pero esto no es lo único que cabe alegar para defender su valor para el sistema político. Dando un paso más en el razonamiento hay que apuntar que el precepto en cuestión, además de tener una finalidad constitucio-

51 Vid., por ejemplo, Álvarez García, H. (2017). «La tutela constitucional de las personas con discapacidad». Revista de Derecho Político, núm. 100, pp. 46-47.

52 Vid. la STC 159/1986, de 16 de diciembre, FJ sexto.

53 FJ segundo.

54 Punto 38 de la Sentencia, en relación con los 25 y 26.

55 Punto 44 de la Sentencia.

(C) UNED. Revista de Derecho Político

N. ${ }^{109}$, septiembre-diciembre 2020, págs. 15-45 
nalmente legítima y relevante, cumple tres condiciones decisivas: la idoneidad, la necesidad y la proporcionalidad ${ }^{56}$.

a) La primera hace referencia a que el artículo 3 de la LOREG resulta útil o funcional para la consecución de esta finalidad. La medida en que consiste - la privación del ejercicio del sufragio en el caso de que en el curso de un proceso de modificación de capacidad o internamiento psiquiátrico se advierta que la persona carece de la mínima capacidad para dicho ejercicio- es coherente con los fines que persigue - la garantía de una participación electoral libre y la protección de la dignidad esencial de las personas con discapacidad intelectual o mental-, es decir, resulta idónea o adecuada para alcanzarlos.

Y ello es así porque la incapacidad electoral que ha de advertir el juez en el caso concreto, y que es la causa de restricción del sufragio, se identifica con la falta de autodeterminación política o electoral, que es una situación en que la persona no está en condiciones de formar una voluntad electoral consciente y libre, de comprender la naturaleza y el efecto de votar y tomar una decisión al respecto, y que la coloca, además, lógicamente, en una situación de gran vulnerabilidad ante terceros a la hora del ejercicio del sufragio ${ }^{57}$. El voto en estas circunstancias de falta absoluta de autodeterminación personal sería, así, en el mejor de los casos, inocuo para la persona afectada en su esfera intelectual y sensitiva, aunque no tanto para la integridad del proceso electoral, y, en el peor, y sin duda más frecuente, claramente perjudicial para ambos, pues expone a la persona a servir de fácil instrumento de captación o, incluso, alteración de su voto por parte de terceros. Privar del ejercicio del voto en esta situación se muestra, pues, como especialmente idóneo y coherente.

b) La segunda condición es la de la necesidad o indispensabilidad del artículo 3 - con la privación del ejercicio del derecho del sufragio que puede suponer- para conseguir dichos fines. Con ello queremos decir que, en el concreto supuesto de hecho al que nos referimos, no hay otra medida alternativa para alcanzarlos que resulte menos invasiva o restrictiva para la posición jurídica fundamental del individuo.

Ello se debe a la razón ya conocida de que la privación del ejercicio del sufragio en aplicación del artículo 3 de la LOREG, interpretado de la forma restrictiva antes indicada, es, precisamente, una medida subsidiaria de las acciones de apoyo. Solo

56 Es la triple dimensión del test de proporcionalidad, aplicable en materia de limitación de los derechos fundamentales, que la magistrada Adela Asua Batarrita había echado de menos en el Auto 196/2016, de 28 de noviembre, que descartó la inconstitucionalidad del artículo 3 de la LOREG (voto particular, punto 4)

57 Sobre la vulnerabilidad de las personas con discapacidad intelectual en el ejercicio del sufragio vid. Gálvez Muñoz, L. A. (2009). El derecho de voto de los discapacitados y otras personas vulnerables. Teoría, crítica y práctica, Valencia, Tirant lo Blanch, pp. 83-84; Gómez Garrido, L. Mª (2018). «El derecho de sufragio activo de las personas con discapacidad intelectual». Almacén de derecho (blog), 28 de diciembre de 2018, disponible en https://almacendederecho.org/el-derecho-de-sufragio-activo-de-las-personas-con-minusvalia-intelectual; y León Alonso, M. (2019). «La Ley Orgánica 2/2018, de 5 de diciembre, de Reforma del Régimen Electoral General: una revisión del concepto de capacidad electoral». IgualdadES, núm. 1, p. 216. 
puede tener lugar cuando dichas acciones ya no son eficaces, es decir, en el caso de que ni con todos los apoyos imaginables que pudieran articularse podría la persona afectada ejercer el derecho de sufragio de forma consciente, libre y voluntaria.

Las medidas de apoyo ya se han agotado y solo queda la privación del sufragio para impedir un voto no acorde a su naturaleza y contrario a los principios constitucionales. Es, pues, la última medida a implementar para preservar los fines mencionados, y, en consecuencia, se presenta como indispensable.

c) La tercera y última condición es la de la proporcionalidad en sentido estricto o justo equilibrio de los intereses en juego. No es solo que la privación del sufragio prevista en el artículo 3 de la LOREG sea idónea y necesaria para conseguir los fines constitucionales señalados, es que también es proporcional, en el sentido de que los beneficios para el sistema constitucional son claramente superiores a los sacrificios y, además, que éstos son los mínimos posibles.

Basta señalar los elementos ya conocidos: que se contribuye de manera eficaz a garantizar la integridad del proceso electoral y la dignidad de las personas afectadas, tras agotar o descartar las acciones de apoyo; que se respeta el contenido esencial del derecho de sufragio e, incluso más, se contribuye a su realización; que no se vulnera ningún precepto constitucional, ni el artículo 14 (principio de igualdad), ni el 23 (principio de universalidad del sufragio), ni el 49 (principio de protección de las personas con discapacidad); y que la ponderación a realizar en cada caso está revestida de la garantía judicial y de los derechos de la tutela judicial y del debido proceso $^{58}$.

\section{IV.- LA DEFICIENTE ARTICULACIÓN DE LA REFORMA}

Llegamos, finalmente, al último punto de crítica a la reforma de la LOREG operada por la Ley Orgánica 2/2018, de 5 de diciembre, y que consiste en poner de manifiesto su deficiente articulación y, en particular, la problemática que plantean las que cabe denominar como disposiciones complementarias de la reforma. Recuérdese que la Ley de reforma además de eliminar las normas que permitían privar del ejercicio de sufragio en el proceso de modificación de capacidad o con ocasión de un internamiento psiquiátrico (artículos 3.1 b) y c) y 3.2), ha realizado otros dos cambios en el texto legal: en primer lugar, ha introducido la prescripción de que «toda persona podrá ejercer su derecho de sufragio activo, consciente, libre y voluntariamente, cualquiera que sea su forma de comunicarlo y con los medios de apoyo que requiera» (artículo 3.2); y, en segundo término, ha ordenado la cesación de efectos de las limi-

58 Otro posible elemento a valorar es el del número de personas afectadas por la aplicación de la norma, de habitual uso en el Tribunal Europeo de Derechos Humanos. En nuestro caso la cifra es reducida, alrededor del 0,25\% del electorado.

(C) UNED. Revista de Derecho Político

N. ${ }^{\circ} 109$, septiembre-diciembre 2020, págs. 15-45 
taciones del sufragio que se hubiesen establecido en las resoluciones judiciales dictadas con anterioridad (disposición adicional octava) ${ }^{59}$.

El objetivo perseguido con estos dos nuevos elementos es loable. Aunque no figura en la exposición de motivos de la Ley se deduce fácilmente del enunciado de cada norma y, además, consta en las intervenciones parlamentarias ${ }^{60}$ : en el primer caso (artículo 3.2) la finalidad de la norma es doble, pues doble es también su contenido: reforzar la seriedad del ejercicio del derecho de sufragio de todo elector («consciente, libre y voluntariamente»), así como facilitar su ejercicio por parte de las personas con discapacidad («cualquiera que sea su forma de comunicarlo y con los medios de apoyo que requiera»); y, en el segundo caso (disposición adicional octava), reintegrar el derecho de sufragio de todas las personas con discapacidad que en el momento de la reforma lo tenían restringido, casi cien mil ${ }^{61}$, evitando así la pervivencia de efectos de una norma derogada restrictiva de derechos, en evidente trasgresión de la doctrina constitucional sobre el artículo 9.3 de la $\mathrm{CE}^{62}$.

No obstante, ninguna de estas dos disposiciones se ha articulado de forma adecuada, como se advirtió por parte de algunos diputados durante la elaboración de la reforma y se puso de manifiesto por la doctrina tras su entrada en vigor $^{63}$. Veamos brevemente dónde radica el problema en cada norma y sus negativos efectos.

a) El nuevo artículo 3.2 de la LOREG, con su llamada a que el sufragio se ejerza «consciente, libre y voluntariamente, cualquiera que sea su forma de comunicarlo y con los medios de apoyo que requiera», presenta un problema de abstracción y, por tanto, de aplicabilidad. Su formulación es excesivamente general y abierta, sin prever instrumentos, sujetos o procedimientos concretos que ordenen la aplicación de las genéricas declaraciones normativas que hace sobre los requisitos del sufragio, la forma de comunicarlo y el apoyo disponible.

Esta generalidad y abstracción de la norma tiene indudables efectos negativos sobre el proceso electoral. Así:

59 El texto completo de esta disposición adicional octava dice así: «A partir de la entrada en vigor de la Ley de modificación de la Ley Orgánica del Régimen Electoral General para adaptarla a la Convención Internacional sobre los Derechos de las Personas con Discapacidad, quedan sin efecto las limitaciones en el ejercicio del derecho de sufragio establecidas por resolución judicial fundamentadas jurídicamente en el apartado 3.1. b) y c) de la Ley Orgánica 5/1985, de 19 de junio, ahora suprimidas. Las personas a las que se les hubiere limitado o anulado su derecho de sufragio por razón de discapacidad quedan reintegradas plenamente en el mismo por ministerio de la ley».

60 Sobre el debate parlamentario vid. Fernández Esquer, C. (2019). «La tramitación parlamentaria de la reforma del sufragio de las personas con discapacidad: elementos para un debate». IgualdadES, núm. 1, pp. 221 y ss.; y Arnaldo Alcubilla, E. (2019). «El reconocimiento del derecho de sufragio de las personas incapacitadas judicialmente», en Guillen, J. (coord.), Libro Homenaje a José Manuel Sala Arquer, Madrid, Congreso de los Diputados, pp. 87 y ss.

${ }_{61}$ En concreto, 98.4888 personas, según la respuesta dada por la Junta Electoral Central al Comité Español de Representantes de Personas con Discapacidad (CERM) el 24 de junio de 2016.

62 Vid. las SSTC 8/1981, de 30 de marzo, 51/1985, de 10 de abril, y 131/1986, de 29 de octubre.

63 Vid, Centro de Estudios Políticos y Constitucionales (2019). Seminario..., op. cit., en particular las intervenciones de Gálvez Muñoz, L. A., y León Alonso, M., pp. 4 y 11. 
- Inseguridad jurídica, pues no está nada claro el alcance de la norma, a qué obliga exactamente, e incluso a quién. Por ejemplo, si la mesa electoral debe o no impedir el voto de un elector si entiende por unanimidad que éste no se encuentra en condiciones de emitir un voto consciente, libre y voluntario. La Junta Electoral Central ha dictado una Instrucción — la 7/2019, de 18 de marzo- que despeja algunas dudas, pero deja otras muchas cuestiones en el aire ${ }^{64}$.

- Conflictividad, como consecuencia inmediata de esta falla en la seguridad jurídica, pues, como es sabido, la indeterminación e incerteza de lo mandado es el mejor caldo de cultivo de la diversidad interpretativa y, por tanto, del conflicto. Estos conflictos surgirán al ejercer el derecho de sufragio en las mesas electorales o incluso antes en el trámite del voto por correo, pero pueden trasladarse después al contencioso-electoral y al amparo electoral, con posible afectación —aunque improbable- de los resultados electorales.

- Ineficacia, pues no parece que el artículo 3.2 de la LOREG, con su abstracción, pueda contribuir de manera apreciable a conseguir sus objetivos, es decir, que el sufragio se emita en las condiciones básicas de conciencia, libertad y voluntariedad que corresponden a su esencia y que se facilite su ejercicio por parte de las personas con discapacidad. Le faltan, precisamente, los instrumentos concretos de garantía que lo harían posible, instrumentos, por ejemplo, como el que ha eliminado la Ley de reforma con la derogación del artículo 3.1 b) y c), pues la posibilidad de privar del ejercicio del sufragio, por falta de capacidad electoral, a las personas sometidas a un proceso de modificación de capacidad o internamiento psiquiátrico, era una garantía concreta de esa exigencia general de emisión consciente, libre y voluntaria, que contribuía de manera efectiva al fin indicado, aunque, es verdad, que claramente perfectible y susceptible, por tanto, de reforma.

b) Por su parte, la disposición adicional octava, que declara el cese de efectos de las limitaciones del derecho de sufragio establecidas en las resoluciones judiciales dictadas en aplicación del artículo 3 de la LOREG y el consiguiente reintegro en su derecho de los afectados, presenta un grave problema de incompletud o insuficiencia, que deteriora gravemente su alcance efectivo: y es que debería haber ido acompañada, necesariamente, de la previsión de que los jueces competentes establecieran los medios de apoyo que en cada caso precisasen estas personas para poder ejercer el derecho de

64 Sobre esta Instrucción vid. Gálvez Muñoz, L. A. (2019). «La exigencia de que el sufragio se ejerza “consciente, libre y voluntariamente» del nuevo artículo 3.2 de la Ley Orgánica del Régimen Electoral General. Dudas interpretativas y pautas de aplicación». IgualdadES, núm. 1, pp. 234 y ss.; y Arnaldo Alcubilla, E. (2019). «El reconocimiento...», op. cit., pp. 135 y ss. 
voto en las condiciones requeridas por la ley de conciencia, libertad y voluntariedad $^{65}$.

El razonamiento es, sustancialmente, el mismo que en el punto anterior, cuando hablábamos de la limitación de eficacia del artículo 3.2 por su generalidad. Ahora, en el caso de la disposición adicional octava, sucede algo similar: para lograr la participación en el proceso electoral de las personas privadas judicialmente hasta ese momento del ejercicio del sufragio, el objetivo último de la norma, no basta con proclamar la cesación de efectos de las resoluciones judiciales en lo que afecta al derecho de sufragio, ya que dichas personas no estaban sometidas a medidas de protección y modificación de capacidad sin motivo, pues sufren de graves anomalías, que al combinarse con el entorno, dificultan su participación efectiva en condiciones de igualdad; era preciso, además, por ello, de manera ineludible, establecer medidas concretas en cada caso que permitieran salvar y paliar sus carencias personales, así como las del entorno físico e institucional, y ayudar al elector a formar y expresar su voluntad electoral de manera adecuada.

No haberlo hecho devalúa inevitablemente el sentido igualitario del conjunto de la Ley de reforma, pues no puede producir el resultado inclusivo esperado con ella y que se manifiesta en su expresivo título de «garantizar el derecho de sufragio de todas las personas con discapacidad», garantía que no puede ser meramente formal, sino también material y efectiva. No es comprensible, además, pues no se ajusta a las exigencias de apoyo propias del modelo social o perspectiva de derechos humanos que inspira la Convención de $2006^{66}$, la actual legislación española en materia de discapacidad y la propia reforma del artículo 3 de la LOREG e incluso el artículo 49 de la $\mathrm{CE}^{67}$ Y todo ello sin entrar de nuevo en la delicada cuestión de la puesta en riesgo que ello ocasione de la integridad y autenticidad del voto de estas personas.

Por lo demás, cabe apuntar una crítica final que trasciende a los dos elementos que acabamos de examinar y que afecta al conjunto de la reforma, y es la total desatención del legislador hacia el derecho de sufragio pasivo de las personas con discapacidad, a pesar de la importancia que reviste esta faceta del sufragio y del amplio margen que existe de actuación ${ }^{68}$. Es incomprensible, pues lo prevé expresamente la

65 El establecimiento de estos medios de apoyo, es, sin embargo, una opción accionable en todo momento, en virtud del artículo 761 de la Ley de Enjuiciamiento Civil, por las personas legitimadas en los procesos de modificación de capacidad, entre ellos el Ministerio Fiscal.

66 Vid. León Alonso, M. (2019). «La Ley...», op. cit., p. 212. Sobre el cambio de modelo que supone la Convención vid. Palacios, A. (2008). El modelo social de discapacidad: orígenes, caracterización y plasmación en la Convención Internacional sobre los derechos de las personas con discapacidad, Madrid, Cinca.

${ }_{67}$ Sobre el ajuste del artículo 49 de la CE a este modelo vid. Anguita Susi, A. (2019). «Realidad y perspectivas del derecho de sufragio activo de las personas con discapacidad intelectual». Teoría y Realidad Constitucional, núm. 44, 2019, pp. 421-423.

68 Vid. Gálvez Muñoz, L. A. (2017). «El régimen de la participación electoral de las personas con discapacidad en los cuarenta años de democracia». Revista de Derecho Político, núm. 100, p. 1093; y Pérez Alberdi, Ma R. (2019). Los derechos de participación..., op. cit., p. 104. 
Convención de Derechos de las Personas con Discapacidad de $2006^{69}$, y, además, se lo requirió, además, a España el Comité de Derechos de las Personas con Discapacidad en 2011, junto con la petición de que modificara la LOREG para conseguir que todas las personas con discapacidad tuvieran derecho a $\operatorname{votar}^{70}$.

\section{V.- BIBLIOGRAFÍA CITADA}

Aláez Corral, Benito (2006). Nacionalidad, ciudadanía y democracia: ¿a quién pertenece la Constitución de 1978?, Madrid, Centro de Estudios Políticos y Constitucionales.

Álvarez García, H. (2017). «La tutela constitucional de las personas con discapacidad». Revista de Derecho Político, núm. 100, pp. 1027-1055.

Anguita Susi, A. (2019). «Realidad y perspectivas del derecho de sufragio activo de las personas con discapacidad intelectual». Teoría y Realidad Constitucional, núm. 44, pp. 417-433.

Arnaldo Alcubilla, E. (2019). «El reconocimiento del derecho de sufragio de las personas incapacitadas judicialmente», en Guillen, J. (coord.), Libro Homenaje a José Manuel Sala Arquer, Madrid, Congreso de los Diputados, pp. 79-143.

AzPitarte SÁnchez, M. (2002). «La dimensión constitucional del procedimiento electoral». Teoría y Realidad Constitucional, núms. 10-11, segundo semestre de 2002-primer semestre de 2003, pp. 425-443.

BARIfFi, F. J. (2013). «Corte Europea de Derechos Humanos: Ejercicio del derecho al voto de personas sujetas a un régimen de tutela (Caso Alajos Kiss vs. Hungría)», en Bariffi, F. J. (coord.), Práctica clínica y litigación estratégica en discapacidad y Derechos Humanos: algunas experiencias de Iberoamérica, Madrid, Dykinson, pp. 457-462.

Barrat Esteve, J. (2017). «Discapacitados mentales y participación política: el derecho de sufragio», en Escobar Roca, G. (ed.), Ombudsman y colectivos en situación de vulnerabilidad. Actas del III Congreso Internacional del PRADPI, Valencia, Tirant lo Blanch, pp. 151-166.

Beckman, L. (2009). The Frontiers of Democracy. The Right to vote and its limits, New York, Palgrave Macmillan.

Centro de Estudios Políticos y Constitucionales (20i9). Seminario: Derecho de sufragio y discapacidad, 3 de abril de 2019, resumen accesible en http://

69 Vid el artículo 29.a) de la Convención.

70 Parte final del Punto 48 de las Observaciones finales del Comité de Derechos de las Personas con Discapacidad, aprobadas el 23 de septiembre de 2011, al Informe presentado por España con arreglo al artículo 35 de la Convención: «... Además, se recomienda que todas las personas con discapacidad que sean elegidas para desempeñar un cargo público dispongan de toda la asistencia necesaria, incluso asistentes personales» (CRPD/C/ESP/CO/1).

(C) UNED. Revista de Derecho Politico

N. ${ }^{\circ} 109$, septiembre-diciembre 2020, págs. 15-45 
www.cepc.gob.es/actividades/agenda/2019/03/06/seminario-derecho-de-sufragio-y-discapacidad.

Cuenca Gómez, P. (2018). «El derecho de voto de las personas con discapacidad intelectual y psicosocial. La adaptación de la legislación electoral española a la Convención Internacional de Derechos de las Personas con Discapacidad». Derechos y libertades, núm. 38, pp. 171-202.

Díaz Alabart, S. (2012). «El derecho de sufragio de las personas con discapacidad. La visión civilista». Revista de Derecho Privado, núm. 96, pp. 3-24.

European Union Agency For Fundamental Rights (2OI9). Who will (not) get to vote in the 2019 European Parliament elections? Developments in the right to vote of people deprived of legal capacity in EU members States, Luxemburgo, FRA.

Fishkin, J. (2011). «Equal Citizenship and the Individual Right to Vote». Indiana Law Journal, vol. 86, pp. 1289-1360.

Gálvez Muñoz, L. A. (2009). El derecho de voto de los discapacitados y otras personas vulnerables. Teoría, crítica y práctica, Valencia, Tirant lo Blanch.

- (2014). «El derecho de sufragio en el siglo Xx». Derechos y Libertades, núm. 31, pp. 163-189.

— (2017). «El régimen de la participación electoral de las personas con discapacidad en los cuarenta años de democracia». Revista de Derecho Político, núm. 100, pp. 1057-1096.

— (2019). «Los pilares de la reforma electoral de 2018 para garantizar el derecho de sufragio de todas las personas con discapacidad». Corts. Anuario de Derecho Parlamentario, núm. 32, pp. 69-107.

- (2019). «La exigencia de que el sufragio se ejerza "consciente, libre y voluntariamente” del nuevo artículo 3.2 de la Ley Orgánica del Régimen Electoral General. Dudas interpretativas y pautas de aplicación». IgualdadES, núm. 1, pp. 235-250.

García RocA, J. (2007). «Declaración de incapacidad y privación del derecho de sufragio activo y pasivo», en Serrano García, I. (coord.), La protección jurídica del discapacitado. II Congreso Regional, Valencia, Tirant lo Blanch.

Gómez Garrido, L. Ma (2018). «El derecho de sufragio activo de las personas con discapacidad intelectual». Almacén de derecho (blog), 28 de diciembre de 2018, disponible en https://almacendederecho.org/el-derecho-de-sufragio-activo-de-las-personas-con-minusvalia-intelectual.

Gómez-Riesco Tabernero De Paz, J. (2017). «La privación del ejercicio de derecho de sufragio activo de las personas con la capacidad modificada judicialmente: comentario al Auto del Tribunal Constitucional 196/2016, de 28 de noviembre». Derecho privado y Constitución, núm. 31, pp. 243-274.

León Alonso, M. (2014). «Los derechos de participación política de las personas con discapacidad: el derecho al voto». Revista Europea de Derechos Fundamentales, núm. 24, pp. 167-193. 
León Alonso, M. (2019). «La Ley Orgánica 2/2018, de 5 de diciembre, de Reforma del Régimen Electoral General: una revisión del concepto de capacidad electoral». IgualdadES, núm. 1, pp. 205-218.

Martínez-Pujalte, A. L. (2015). Derechos fundamentales y discapacidad, Madrid, Cinca.

- (2016). «Derechos en conflicto, conflicto de derechos: principales fricciones entre la Convención Internacional sobre los Derechos de las Personas Con Discapacidad y la legislación nacional española», en Pérez Bueno, L.C. y Lorenzo García, R. de (dirs.), La Convención Internacional sobre los Derechos de las Personas con Discapacidad: 2006-2016 una década de vigencia, Madrid, Cinca, pp. 149-186.

Palacios, A. (2008). El modelo social de discapacidad: orígenes, caracterización y plasmación en la Convención Internacional sobre los derechos de las personas con discapacidad, Madrid, Cinca.

Pascual Planchuelo, V. C. (2016). «El derecho de voto de las personas con discapacidad y, en especial, de las personas con discapacidad psíquica o intelectual en Derecho Internacional. Su recepción en España». Revista Española de Discapacidad, 4 (1), pp. 101-122.

PÉrez Alberdi, Ma R. (2013). El derecho fundamental a participar en los asuntos públicos, Madrid, Congreso de los Diputados.

- (2019). «Los derechos de participación política de las personas con discapacidad». Lex Social. Revista Jurídica de los derechos sociales, vol. 9, núm. 1, pp. 83-107.

Presno Linera, M. Á. (2003). El derecho de voto, Madrid, Tecnos.

- (2011). El derecho al voto: un derecho político fundamental, disponible en http:// presnolinera.wordpress.com/elderechodevotounderechopolíticofundamental.pdf.

Rivas VAÑó, A. (2018). «Discapacidad intelectual y derecho al sufragio: la inacción del Tribunal Constitucional español», en Caruso Fontán, $\mathrm{M}^{\mathrm{a}} \mathrm{V}$. y Pérez Alberdi, $\mathrm{M}^{\mathrm{a}} \mathrm{R}$. (dirs.), Diálogos judiciales en el sistema europeo de protección de derechos: una mirada multidisciplinar, Valencia, Tirant lo Blanch, pp. 273-289.

Solozábal Echavarría, J. J. (2004). «La actuación efectiva del proceso electoral y sus posibilidades». Revista Española de Derecho Constitucional, núm. 70, pp. 127160.

VyHnáneK, L. (2014). «Mental disability and the right to vote in Europe: a few notes on the recents devolement». International Journal of Disability Studies, vol. 7, núm. 1, 113-133. 
Title:

A critical vision of the Organic Law 2/2018, of 5 December, to reform the LOREG to guarantee the right to vote of all persons with disabilities

\title{
Summary
}

I.- INTRODUCTION. II. - THE FALLACY OF THE OBLIGATION TO REFORM. II.1. International level.II.2. Constitutional level. III. THE UNFAIR DEVALUATION OF THE REFORMED ARTICLE 3 OF THE LOREG. III.1. Constitutionally relevant purpose. III.2. Suitability, necessity and proportionality. IV. - POOR ARTICULATION OF THE REFORM. V.- BIBLIOGRAPHY CITED

\section{Resumen:}

En este trabajo se realiza un análisis abiertamente crítico de la Ley Orgánica 2/2018, de 5 de diciembre, de reforma de la Ley Orgánica 5/1985, de 19 de junio, del Régimen Electoral General, para garantizar el derecho de sufragio de todas las personas con discapacidad, y en virtud de la cual se ha suprimido la previsión de evaluación de la capacidad para ejercer el sufragio de las personas objeto de un proceso de modificación de capacidad o de internamiento psiquiátrico, además de dejar sin efecto las resoluciones judiciales vigentes de incapacidad electoral e introducir una declaración general sobre el ejercicio del sufragio. La crítica a la Ley de reforma se estructura en torno a tres argumentos: primero, la falacia de la incompatibilidad de la previsión derogada con la Convención de Derechos de las Personas con Discapacidad de 2006 y la Constitución; segundo, la injusta desconsideración, por el contrario, del papel que esta norma cumplía en el sistema jurídico en términos de derechos y bienes constitucionales; $y$, tercero, la forma inadecuada en que se han articulado las disposiciones complementarias, con los negativos efectos jurídicos que ello conlleva.

\begin{abstract}
:
This paper includes an openly critical analysis of Organic Law 2/2018, of 5 December, amending Organic Law 5/1985, of 19 June, on the general electoral regime, in order to guarantee the right to vote of all persons with disabilities, and by which the provision for assessment of the capacity to vote of persons undergoing capacity modification or psychiatric detention has been abolished, in addition to repealing existing court decisions on electoral incapacity and introducing a general declaration on the exercise of suffrage. The critique of the Reform Act is structured around three arguments: first, the fallacy of the incompatibility of the derogated provision with the 2006 Convention on the Rights of Persons with Disabilities and the Constitution; second, the unjust disregard, on the contrary, the role that this rule played in the legal system in terms of constitutional rights and property; and, thirdly, the inadequate way in which the comple-
\end{abstract}


mentary provisions have been articulated, with the negative legal effects that this entails.

\section{Palabras clave:}

Derecho de sufragio; elecciones; sufragio universal; igualdad; discriminación; discapacidad.

\section{Keywords}

Right to vote; elections; universal suffrage; equality; discrimination; disability. 
